\title{
Induction of Calcium Sensing Receptor in Human Colon Cancer Cells by Calcium, Vitamin D and Aquamin: Promotion of a More Differentiated, Less Malignant and Indolent Phenotype
}

\author{
Navneet Singh, ${ }^{1}$ Muhammad N. Aslam, ${ }^{2}$ James Varani, ${ }^{2}$ and Subhas Chakrabarty ${ }^{\mathbf{*}}$ \\ ${ }^{1}$ Department of Microbiology, Immunology and Cell Biology Simmons Cancer Institute, Southern Illinois University School of \\ Medicine, Springfield, IIllinois \\ ${ }^{2}$ Department of Pathology, University of Michigan Medical School, Ann Arbor, Michigan
}

\begin{abstract}
The calcium sensing receptor (CaSR) is a robust promoter of differentiation in colonic epithelial cells and functions as a tumor suppressor. Cancer cells that do not express CaSR (termed CaSR null) are highly malignant while acquisition of CaSR expression in these cells circumvents the malignant phenotype. We hypothesize that chemopreventive agents mediate their action through the induction of CaSR. Here, we compare the effectiveness of $\mathrm{Ca}^{2+}$, vitamin $\mathrm{D}$, and Aquamin (a marine algae product containing $\mathrm{Ca}^{2+}$, magnesium and detectable levels of 72 additional minerals) on the induction of $\mathrm{CaSR}$ in the CBS and HCT116 human colon carcinoma cell lines and the corresponding CaSR null cells isolated from these lines. All three agonists induced CaSR mRNA and protein expression and inhibited cellular proliferation in the parental and CaSR null cells. Aquamin was found to be most potent in this regard. Induction of CaSR expression by these agonists resulted in demethylation of the CaSR gene promoter with a concurrent increase in CaSR promoter reporter activity. However, demethylation per se did not induce CaSR transcription. Induction of CaSR expression resulted in a down-regulated expression of tumor inducers and up-regulated expression of tumor suppressors. Again, Aquamin was found to be most potent in these biologic effects. This study provides a rationale for the use of a multi-mineral approach in the chemoprevention of colon cancer and suggests that induction of CaSR may be a measure of the effectiveness of chemopreventive agents. ( 2013 Wiley Periodicals, Inc.
\end{abstract}

Key words: calcium; vitamin D; aquamin; CaSR; chemoprevention

\section{INTRODUCTION}

The extracellular calcium sensing receptor (CaSR) is a 7-transmembrane -spanning G-protein coupled receptor originally identified in the parathyroid gland $[1,2]$. In the parathyroid, CaSR function unequivocally as a calcium sensor, where it senses minute changes in extracellular calcium concentration and regulate the secretion of parathyroid hormone accordingly to maintain $\mathrm{Ca}^{2+}$ homeostasis [1-3]. CaSR is expressed in a variety of tissues and cell type not involved in $\mathrm{Ca}^{2+}$ regulation [4-7]. CaSR is expressed in the colonic epithelium and recent studies suggest that CaSR is a robust promoter of differentiation in the colon and functions as a tumor suppressor [8-15]. We have initially shown that loss of CaSR expression correlates with the phenotype of undifferentiated and invasive human colon tumors and activation of $\beta$-catenin signaling in these tumors $[8,9,11]$. Other groups have reported on the lack of CaSR expression (both mRNA and protein), methylation of CpG islands in the CaSR gene promoter and activation of $\beta$-catenin in advanced colon cancer [16]. Intestinal specific CaSR knock out in mice results in hyperproliferation, expansion of the proliferation zones, changes in crypt structures and enhanced $\beta$-catenin nuclear localization; establishing a definitive negative cross talk between CaSR and $\beta$ catenin signaling in the colonic epithelium [13]. Loss of CaSR is regarded as a key event in the pathogenesis of colon cancer [12].

Loss of CaSR expression may allow cellular escape from $\mathrm{Ca}^{2+}$ mediated growth control. In the colonic crypts, stem cells in the basal zone of a crypt do not

\footnotetext{
Abbreviations: CaSR, calcium sensing receptor; EMT, epithelial mesenchymal transition; hESC, human embryonic stem cell culture medium; TGF $\beta-\mathrm{RI}$ and RII, transforming growth factor $\beta$ receptor I and receptor II.

This work was performed by Navneet Singh in partial fulfillment for the degree of doctor of philosophy, Southern Illinois University, School of Medicine, Springfield, IL.

Conflict of interest: None.

Grant sponsor: Association for International Cancer Research, St. Andrews, Scotland; Grant number: 11-077

*Correspondence to: Simmons Cancer Institute, Southern Illinois University, School of Medicine, Springfield, IL 62794-9677.

Received 24 October 2013; Accepted 26 November 2013

DOI 10.1002/mc.22123

Published online 17 December 2013 in Wiley Online Library (wileyonlinelibrary.com).
} 
express CaSR [9]. Colonic crypt cells gain CaSR expression as they migrate and differentiate upwards in the direction of the lumen $[9,12]$. Exactly what triggers CaSR expression as the colonic crypt cells migrate and differentiate in the crypt is not known. Human colon carcinoma cell lines express CaSR, albeit the expression profile is heterogeneous with cells showing different levels of CaSR expression [14,17]. Although extracellular $\mathrm{Ca}^{2+}$ can up-regulate CaSR expression and induces a more differentiated and benign phenotype in these cell lines $[8,9,11,17]$, a small percentage of cells in a cell line (similar to colonic crypt stem cells) do not express CaSR (termed CaSR null). We have recently isolated and characterized CaSR null cells from the human colon carcinoma CBS and HCT116 cell lines and demonstrated that the null status of these cells can be maintained in supplemental human embryonic stem cell (hESC) culture medium. These CaSR null cells possess a myriad of molecular features that underlie a highly malignant phenotype [14]. Thus, CaSR null cells maintained in hESC medium offer an in vitro model in determining the triggers and the underlying mechanisms of CaSR induction that may reflect on mechanisms applicable to cells in the colonic crypt in vivo.

Dietary calcium and vitamin D possess chemopreventive properties against colon cancer and vitamin $\mathrm{D}$ also acts to promote calcium absorption in the gut $[8,9,11,18]$. Both $\mathrm{Ca}^{2+}$ and vitamin $\mathrm{D}$ have been reported to act through CaSR to mediate their growthinhibitory and differentiation-promoting effects $[8,9,11,17,19]$. Activation of CaSR by $\mathrm{Ca}^{2+}$ or other CaSR agonists suppresses the malignant phenotype of human colon carcinoma cells through effects on a variety of cellular and molecular events. Activation of CaSR inhibits cell proliferation; invasion and anchorage-independent growth $[8,9,11,14,17,19]$; promotes the expression of the tumor suppressor E-cadherin $[8,10,11,20]$; up-regulates the expression of the growth-inhibitory and differentiation related p21/Waf 1 cell cycle check point protein; up-regulates the expression of $\gamma$-catenin and $\mathrm{p} 27 / /^{\text {Kip1 }}$; suppresses the malignancy-associated $\beta$-catenin/Wnt, c-myc and cyclin D1 pathways $[8,10,11,20]$; and reduces levels of thymidylate synthase and survivin which are key molecules contributing to drug resistance in colon cancer $[17,19,21,22]$.

We hypothesize that as the colonic crypt cells migrate up the crypt, they become increasingly exposed to the colonic fluid in the lumen and components in the colonic fluid trigger the induction of CaSR expression. Both $\mathrm{Ca}^{2+}$ and vitamin $\mathrm{D}$ are good candidates because both $\mathrm{Ca}^{2+}$ and vitamin $\mathrm{D}$ have been shown to stimulate CaSR expression in the parental CBS and HCT116 human colon carcinoma cells $[8,9,17,19]$. A variety of other cationic minerals in the colonic fluid may also serve as good candidates in the induction of CaSR. Of interest is Aquamin- that is, the calcium-rich, multi-mineral containing remains of the red marine algae, Lithothamnion calcareum. Aquamin has been shown to induce differentiation in colon carcinoma cells [23] and possess chemopreventive properties against colon polyp formation in mice fed a high fat diet $[23,24]$. Both in vitro and in vivo, Aquamin was more effective than $\mathrm{Ca}^{2+}$ alone at comparable levels.

In this report, we first compared the potency of $\mathrm{Ca}^{2+}$, vitamin $\mathrm{D}$, and Aquamin in inhibiting cell growth and inducing CaSR expression in the heterogeneous human colon carcinoma CBS and HCT116 cell lines maintained in conventional culture medium. We then compared the potency of the same agonists in growth inhibition and CaSR induction in the CaSR null cells (isolated from these cell lines and their null status maintained in embryonic stem cell hESC medium) that is, to determine if these agonists can overcome the constraint on CaSR expression exerted by the hESC medium. Aquamin was found to be more robust than either of the other agonists in growth inhibition and CaSR induction. This was seen with both the parental lines and the CaSR null cells derived from the two lines. Demethylation of CpG islands in the CaSR gene promoter was associated with CaSR induction with all three agonists. Aquamin was most robust in the induction of demethylation by comparison. Surprisingly, demethylation of CpG islands per se was not sufficient in CaSR induction and gene transcription. Suppression of the molecular features associated with the malignant CaSR null phenotype was a consequence, and again, Aquamin was more potent than $\mathrm{Ca}^{2+}$ alone or vitamin $\mathrm{D}$. These results provide a rationale for the use of a multi-mineral approach in the chemoprevention of colon cancer. Induction of CaSR expression may be a measure of the effectiveness of a chemopreventive agent.

\section{MATERIALS AND METHODS}

\section{Cell Culture}

Human colon carcinoma CBS and HCT116 cells were maintained in supplemental minimum essential medium (SMEM). SMEM is essentially $\mathrm{Ca}^{2+}$-free, Minimum Essential Medium Eagle Joklik Modification with L-glutamine (Sigma, St. Louis, MO) supplemented with sodium bicarbonate, peptone, vitamins, amino acids, and 5\% fetal bovine serum. Because serum contains $\mathrm{Ca}^{2+}$, the complete SMEM medium supplemented with serum contains a low amount of $\mathrm{Ca}^{2+}(0.175-0.2 \mathrm{mM})[17,25]$. These cell lines were originally developed from primary human colon tumors by Dr. Michael G. Brattain [26]. CaSR null cells were isolated from the heterogeneous parental CBS and HCT116 cells by magnetic cell sorting and maintained in serum free, bovine serum albumin containing hESC culture supplemented with $10 \mathrm{ng} /$ $\mathrm{mL}$ Nodal and $10 \mathrm{ng} / \mathrm{mL}$ Noggin as previously described [14]. Aquamin is a multi-mineral- 
containing natural product obtained from the skeletal remains of Lithothamnion sp. of red marine algae [23] and consists entirely of the inorganic minerals accumulated from seawater by the organism (Marigot Ltd, Cork, IR). The product contains approximately $12 \%$ calcium and $1 \%$ magnesium, but also has detectable levels of 72 other trace minerals. The concentration of Aquamin used in this study was based on its calcium content.

\section{Cell Proliferation Assay}

Proliferation assays were performed as described previously in six-well culture plates [19]. Parental and CaSR null cells were seeded into their corresponding culture media with or without $\mathrm{Ca}^{2+}$, vitamin $\mathrm{D}$ or Aquamin, dissolved in culture medium, in the concentrations as indicated in the figures. After $48 \mathrm{~h}$ of culture, cellular proliferation was determined by counting the number of viable cells using an automatic Vi-Cell ${ }^{\mathrm{TM}}$ XR Cell Viability Analyzer (Beckman Coulter, Fullerton, CA). Results shown represent the mean and standard error of triplicate experiments.

\section{Real-Time RT-PCR}

This procedure was performed as described previously [14]. Total RNA was extracted from $2 \times 10^{6}$ pelleted parental or their corresponding CaSR null cells by Tri reagent (Sigma). cDNA was synthesized from $4 \mu \mathrm{g}$ of total RNA using a cDNA synthesis kit according to the manufacturer's instructions (Fermentas life sciences, Glen Burnie, MD). Real time RT-PCR was performed using the SYBR green PCR amplification kit (Promega, Madison, WI) in a real time PCR machine with specific primers for the target genes. $\beta$-actin was used as internal controls for equal loading of RNA in all real time RT-PCR experiments. A comparative threshold cycle $\left(\mathrm{C}_{t}\right)$ was used to determine the level of gene expression relative to control and fold expression was calculated using the $\delta$ $\delta$ cycle threshold $\left(C_{t}\right)$ method [14]. Results shown represent the mean and standard error of triplicate independent experiments.

\section{Western Analysis}

Quantitative immunoblottings were performed as previously described using primary anti-CaSR and fluorescent labeled secondary antibodies $[14,17]$. A LICOR ODYSSEY (LI-COR Biosciences, Lincoln, NE) instrument was used to detect and analyze the binding of antibodies to protein of interest. Densitometric fold increase or decrease in protein expression was calculated by comparison to control lanes with an assigned value of one.

\section{Luciferase Reporter Assays}

Luciferase reporter assays were performed as described previously $[9,19]$. Briefly, cells were seeded in 24 -well culture plate and transfected with $1 \mu \mathrm{g}$ of CaSR promoter 1 (P1) or promoter 2 (P2) luciferase reporter construct and $0.1 \mu \mathrm{g}$ of Renilla luciferase reporter construct using Lipofectamine ${ }^{\mathrm{TM}} 2000$ (Invitrogen Life Technologies) transfection reagent. $\mathrm{Ca}^{2+}(1.4 \mathrm{mM})$ or vitamin $\mathrm{D}(1 \mu \mathrm{M})$ or Aquamin $(1.4 \mathrm{mM})$ was added $24 \mathrm{~h}$ after transfections. Luciferase activities were measured at $48 \mathrm{~h}$ after $\mathrm{Ca}^{2+}$ or vitamin $\mathrm{D}$ or Aquamin treatment. Transfection efficiency were determined and normalized by Renilla luciferase activities. Data shown represent the mean and standard error of the mean of triplicate experiments.

Bisulfite Treatment and Methylation Specific PCR

Genomic DNA isolation and methylation specific PCR (MSP) was performed according to previously described procedures [27]. MethPrime computational software was used to predict the CpG methylation sites in the CaSR promoter [28]. Thirty-four major CpG sites were identified in the 694-bp fragment of the CaSR promoter including the transcriptional start site $[21,28]$. Genomic DNA was treated with sodium bisulfite using a CpGenome ${ }^{\mathrm{TM}}$ Turbo bisulfite modification kit (EMD Millipore, Billerica, MA) according to instructions provided by the manufacturer. In the sodium bisulfite reaction, all unmethylated cytosines were converted to uracils, while 5-methylcytosines are resistant to this modification and remain unaltered. MSP analysis was performed using primers targeting the CaSR promoter region. Following bisulfite treatment, two sets of MSP primers were used which were designed specifically to amplify either a bisulfitesensitive (unmethylated) strand or a bisulfite-resistant (methylated) strand. The forward and reverse primer sequences for the unmethylated strand were (GAGTTTATTTTTGTGGAGATTTATGG) and (CCAACATATACCCCTCATTCAAC), respectively. The forward and reverse primer sequences for the methylated strand were (GAGTTTATTTTCGTGGAGATTTACG) and (GACGTATACCCCTCGTTCGA), respectively. As an additional control, cells were treated with $1 \mathrm{uM}$ 5-aza-2'-deoxycytidine (5-aza-dc; Sigma Chemical, Co., St. Louis, MO) for $48 \mathrm{~h}$ to induce DNA demethylation. DNA from 5-aza-dc-treated cells was also analyzed by MSP. PCR amplified products were analyzed by agarose gel (2\%) electrophoresis.

\section{Statistical Analyses}

Statistical analyses were performed using GraphPad Prism software. Results were expressed as mean \pm SE. Statistical significance was calculated by using Student's unpaired $t$-test. $P \leq 0.05$ indicates a significant difference by comparison with controls.

\section{RESULTS}

Inhibition of Cellular Proliferation and Induction of CaSR Expression in Parental CBS and HCT116 Cells

$\mathrm{Ca}^{2+}$, vitamin $\mathrm{D}$, and Aquamin each inhibited cellular proliferation in a dose dependent manner 
(Fig. $1 \mathrm{~A}$ and B). Side-by-side comparison of the antiproliferative effect of $\mathrm{Ca}^{2+}$ and Aquamin (from physiologic $1.4 \mathrm{mM}$ to supra-physiologic $7.0 \mathrm{mM}$ ) demonstrated that Aquamin was more potent than $\mathrm{Ca}^{2+}$ in inhibiting cell proliferation. The major ingredient of Aquamin (in addition to containing many other minerals) is $\mathrm{Ca}^{2+}$. Therefore, an amount of Aquamin that is equivalent to $1.4 \mathrm{mM} \mathrm{Ca}^{2+}$ is of physiologic relevance. Vitamin D (from physiologic $0.01 \mu \mathrm{M}$ to supra-physiologic $1.0 \mu \mathrm{M}$ ) also inhibited cell proliferation while $1 \mu \mathrm{M}$ concentration was found to be most potent.

Both $\mathrm{Ca}^{2+}$ and Aquamin induced a high level of CaSR mRNA expression while vitamin D was relatively less effective by comparison (Fig. 1C and D). At high concentrations of either $\mathrm{Ca}^{2+}$ or Aquamin no
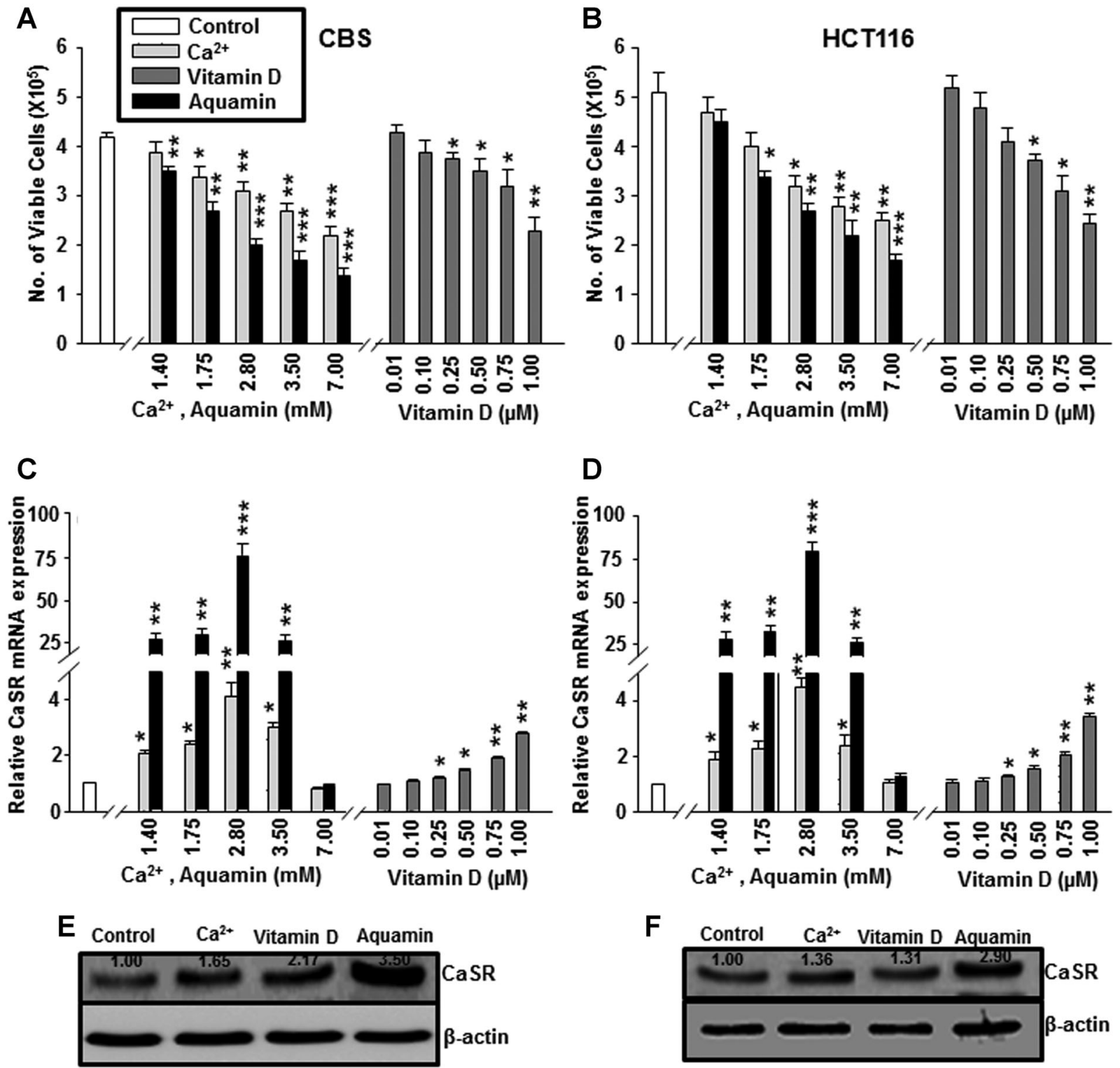

Figure 1. Inhibition of cell proliferation and induction of CaSR expression in parental CBS and HCT116 carcinoma cell lines. A and B, cell proliferation. Proliferation assay was performed as described in Methods in conventional SMEM culture medium. The effect of $\mathrm{Ca}^{2+}$ vitamin D or Aquamin treatment on cell proliferation was compared to that of untreated control cells. Results are expressed as number of viable cells at the end of the culture period. Triplicate determinations were performed in each experiment and the values shown represent the mean and standard error of three independent experiments. $C$ and $D$, Real time RT-PCR analysis of the expression level of mRNA encoding

CaSR relative to that of untreated control cells. Results represent the mean and standard error of the mean of triplicate determinations. $\beta$ actin was used as loading control. A-D, asterisk $\left(^{*}\right)$ indicates the results are of statistical significance. ${ }^{*} P<0.05$ significant: ${ }^{* *} P<0.01$ very significant; ${ }^{* * *} P<0.001$ extremely significant. $\mathrm{E}$ and $\mathrm{F}$, Western blot analysis of CaSR expression. Cells were treated for $48 \mathrm{~h}$ with $\mathrm{Ca}^{2+}(1.4 \mathrm{mM})$, vitamin $\mathrm{D}(1.0 \mu \mathrm{M})$ or Aquamin $\left(1.4 \mathrm{mM} \mathrm{Ca}^{2+}\right)$ for $48 \mathrm{~h}$. Protein expression was normalized and compared to untreated controls with an assigned value of 1.0. $\beta$-actin was used as loading control. 
induction of CaSR mRNA was seen, but this may reflect toxicity. At equal molar concentrations (below the $7.0 \mathrm{mM}$ level), Aquamin was more potent in CaSR mRNA induction than $\mathrm{Ca}^{2+}$. Vitamin $\mathrm{D}$ at $1 \mu \mathrm{M}$ concentration also induced CaSR mRNA while lower concentrations were not effective. Next, we compared the effectiveness of these agents in inducing CaSR protein expression-that is, by $\mathrm{Ca}^{2+}$ at $1.4 \mathrm{mM}$, vitamin $\mathrm{D}$ at $1.0 \mu \mathrm{M}$ and Aquamin containing $1.4 \mathrm{mM} \mathrm{Ca}^{2+}$. Aquamin induced the highest level of CaSR protein expression by comparison to $\mathrm{Ca}^{2+}$ or vitamin D (Fig. 1E and F).

Inhibition of Cellular Proliferation and Induction of CaSR Expression in CaSR Null Cells Isolated From the Parental CBS and HCT116 Cells

Next, we compared the efficacy of $\mathrm{Ca}^{2+}(1.4 \mathrm{mM}$, physiologic concentration), vitamin $\mathrm{D}(1.0 \mu \mathrm{M})$, and Aquamin (1.4 $\mathrm{mM} \mathrm{Ca}^{2+}$, physiologic concentration) in inhibiting cell proliferation and CaSR induction in the highly malignant CaSR null cells cultured in hESC culture medium. We wanted to determine if these agents could overcome the constraint exerted by hESC medium in maintaining the null phenotype. All three agents could inhibit cell growth (Fig. 2A and B) and induce CaSR expression at the mRNA (Fig. 2C and D) and protein levels (Fig. 2E and F). Aquamin was found to be much more effective in this regard than either $\mathrm{Ca}^{2+}$ alone or vitamin $\mathrm{D}$, while vitamin $\mathrm{D}$ at $1.0 \mu \mathrm{M}$ concentration was slightly more effective by comparison to $1.4 \mathrm{mM} \mathrm{Ca}^{2+}$.

Demethylation of CaSR Promoter CpG Sites

MethPrimer computational software had predicted the CpG methylation sites in the CaSR promoter and thirty-four major CpG sites have been identified in the 694-bp fragment of the CaSR promoter including the transcriptional start site [21]. We have previously reported that methylation of $\mathrm{CpG}$ islands could be responsible for maintaining the null status of CaSR null cells cultured in human embryonic stem cell culture medium as these sites were demethylated and CaSR expression was induced when the null cells were placed in conventional SMEM culture medium containing fetal bovine serum [21]. Here we determined whether $\mathrm{Ca}^{2+}$, vitamin $\mathrm{D}$, or Aquamin could also induce demethylation of the CaSR promoter in CaSR null cells cultured in hESC culture medium. MSP analysis of CaSR null cells revealed the presence of methylated PCR product with or without sodium bisulfite treatment (Fig. $3 \mathrm{~A}$ and $\mathrm{B}$ ) while 5-aza-dc treatment induced demethylation of these CpG islands along with the detection of unmethylated PCR product (Fig. $3 \mathrm{~A}$ and B). Figure $3 \mathrm{C}$ and D, lanes 3 , 4 , and 5 shows the increase in unmethylated PCR products upon treatment with $\mathrm{Ca}^{2+}$, vitamin $\mathrm{D}$, or Aquamin. Figure 3C and D, lanes 1 shows methylated PCR product in the CaSR null cells and lanes 2 shows unmethylated PCR product in the null cells treated with 5-aza-dc. In conjunction with promoter demethylation, CaSR promoter reporter assays revealed an increase in the activation of both the P1 (Fig. $3 \mathrm{E}$ and F) and P2 (Fig. $3 \mathrm{G}$ and $\mathrm{H}$ ) promoters of the CaSR gene when the null cells were treated with $\mathrm{Ca}^{2+}$, vitamin $\mathrm{D}$, or Aquamin. Overall, Aquamin was relatively more robust in the demethylation of $\mathrm{CpG}$ islands in the CaSR promoter and, concomitantly, more potent in the transcriptional up-regulation of both the P1 and $\mathrm{P} 2$ promoter of the CaSR gene. The results were similar with both cell lines. However, we found that 5AZA-dc treatment per se did not induce CaSR transcription. Thus, demethylation of CpG islands alone was not sufficient to induce CaSR transcription.

Changes in the Molecular Phenotype of CaSR Null Cells by $\mathrm{Ca}^{2+}$, Vitamin D, or Aquamin

Isolated CaSR null cells maintained in hESC culture medium possess a myriad of molecular features that are associated with the malignant phenotype [14]. CaSR null cells, however, regain CaSR expression when these cells were seeded into conventional culture medium containing FBS with a concurrent suppression of the malignancy associated molecular features [21]. More importantly, changes in the molecular features of the null cells is directly linked to the induction of CaSR expression because blocking CaSR induction by shRNA negated these changes [21]. . Here, we determined if induction of CaSR expression in the CaSR null cells (cultured in hESC culture medium) by $\mathrm{Ca}^{2+}$, vitamin $\mathrm{D}$, or Aquamin would be sufficient to change the molecular features of the CaSR null cells. Parental cell lines were used as controls which represent the gene expression profile of these cell lines. The majority of the cells in the parental lines express CaSR with only a small percentage that are CaSR null [14]. RT-PCR was used in this analysis at the RNA level. Indeed, treatment of the null cells by $\mathrm{Ca}^{2+}$, vitamin $\mathrm{D}$, or Aquamin down-regulated the expression of malignancy associated EMT molecules ( $\mathrm{N}$-cadherin, $\beta$ catenin, fibronectin and vimentin); EMT associated transcription factors (Snail-1, Snail-2, and Twist); oncogenic miRNAs (miR-21, miR-135a and miR135b) and drug resistant protein survivin and TS (Fig. 4A and C). Aquamin was found to be most potent in this regard. In addition to the downregulated expression of the malignancy associated molecules described above, $\mathrm{Ca}^{2+}$, vitamin $\mathrm{D}$, or Aquamin up-regulated expression of tumor suppressive molecules E-cadherin, miR-145 and TGF $\beta$-R1 and TGF $\beta-R 2$ (Fig. 4 B and D). Again, Aquamin was found to be most potent in this regard.

\section{DISCUSSION}

The expression of CaSR in both the CBS and HCT116 cell lines is heterogeneous-that is, with cells expressing different levels of CaSR $[14,17]$. We previously isolated CaSR null cells from both parental 


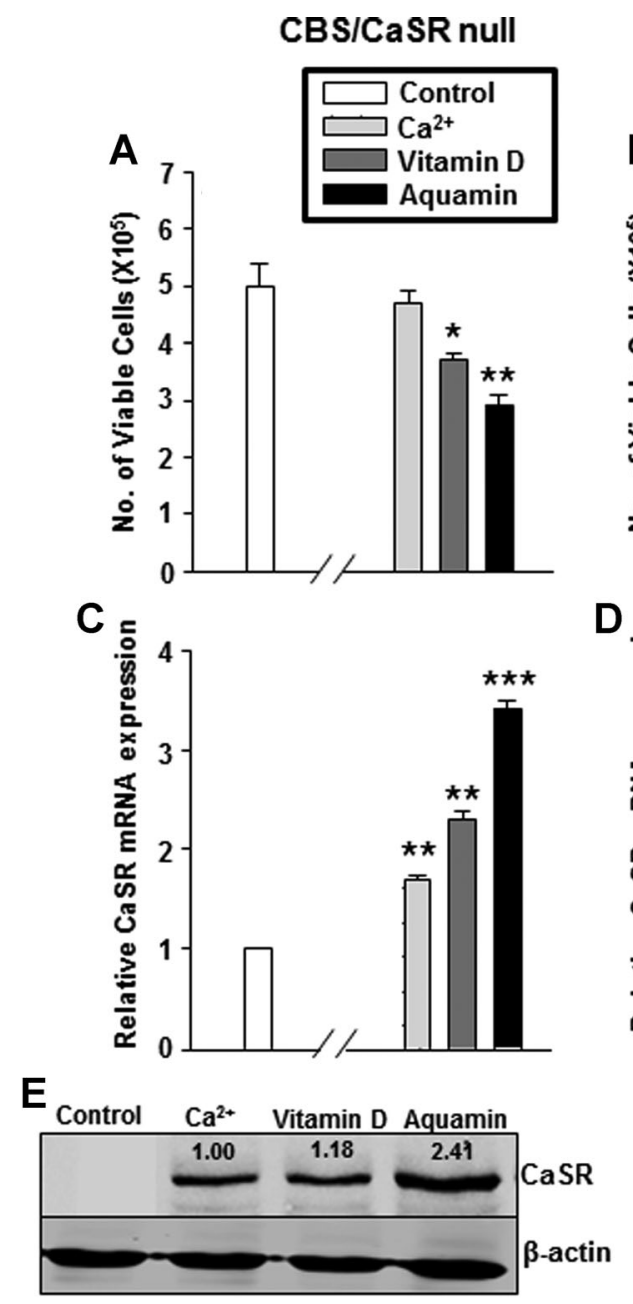

Figure 2. Inhibition of cell proliferation and induction of CaSR expression in CaSR null cells isolated from the CBS and HCT116 cell lines. $A$ and $B$, cell proliferation. This assay was performed with the CaSR null cells cultured in hESC culture medium. Cells were treated with $\mathrm{Ca}^{2+}(1.4 \mathrm{mM})$, vitamin $\mathrm{D}(1.0 \mu \mathrm{M})$ or Aquamin $\left(1.4 \mathrm{mM} \mathrm{Ca}{ }^{2+}\right)$ for $48 \mathrm{~h}$. Cultures without treatment served as controls. The results presented here, number of viable cells; represent the mean and standard error of the mean of triplicate experiments. C and D, induction of CaSR mRNA in CaSR null cells cultured in hESC culture medium. The expression level of mRNA encoding CaSR relative to that of untreated control cells was determined by real time RT-PCR CaSR null cells were treated with $\mathrm{Ca}^{2+}(1.4 \mathrm{mM})$, vitamin $\mathrm{D}(1.0 \mu \mathrm{M})$, or

cell lines and demonstrated that the null status of these cells was maintained in hESC culture medium. CaSR null cells were found to possess a myriad of cellular and molecular features that are linked to a highly malignant and drug resistant phenotype [14]. Of interest, CaSR null cells were able to differentiate and acquire CaSR expression with a concurrent reversal of the CaSR null molecular phenotype when these cells were seeded into conventional culture medium containing fetal bovine serum [21]. The change in phenotype requires the induction of CaSR expression [21] as phenotypic changes did not occur when CaSR induction was prevented. The coexistence of CaSR null cells with cells that express

\section{HCT116/CaSR null}
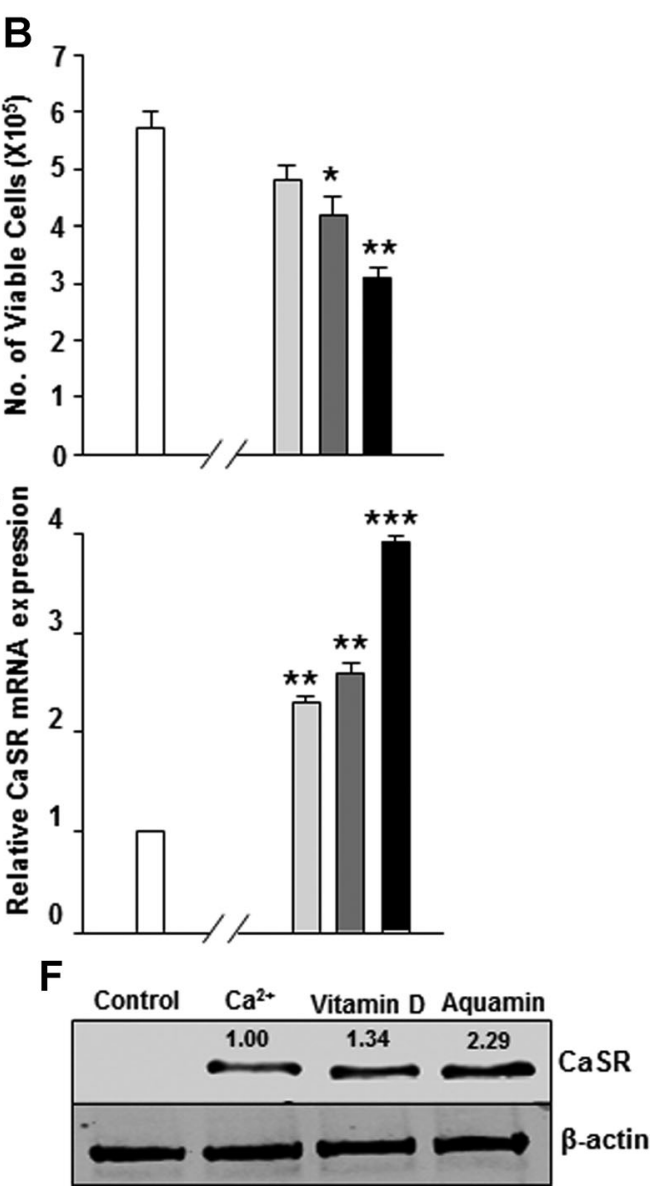

Aquamin $\left(1.4 \mathrm{mM} \mathrm{Ca}^{2+}\right)$ for $48 \mathrm{~h} . \beta$-actin was used as loading control. Triplicate assays were performed in each experiment and the values shown represent the mean and standard error of three independent experiments. A-D, asterisk $\left(^{*}\right)$ indicates the results are of statistical significance. ${ }^{*} P<0.05$ significant; ${ }^{* *} P<0.01$ very significant; ${ }^{* * *} P$ $<0.001$ extremely significant. E and $F$, Western blot analysis of CaSR protein expression from CaSR null cells treated with $\mathrm{Ca}^{2+}$, vitamin $\mathrm{D}$ or Aquamin as described above. $\beta$-actin was used as loading controls. As shown, untreated CaSR null cells do not express CaSR [14]. The level of protein expression in cells treated with vitamin D or Aquamin was compared to that of the $\mathrm{Ca}^{2+}$ treated cells with an assigned value of 1.0

various levels of CaSR could indicate a stem-like nature of the CaSR null phenotype. We have hypothesized that CaSR null cells possess stem-like property, resembling that of the colonic crypt stem cells in vivo which are CaSR null [14]. The expression of CaSR in the parental CBS and HCT116 cells is extremely heterogeneous with cells expressing a very low level of CASR to cells that express a very high level of CaSR [14]. We hypothesize that a dynamic process of cell death and revival occurs in a culture and that CaSR null cells divide asymmetrically to replenish themselves and also differentiate into CaSR positive cells which will eventually apoptose and die. The expression profile of stem cell markers and survival 
A

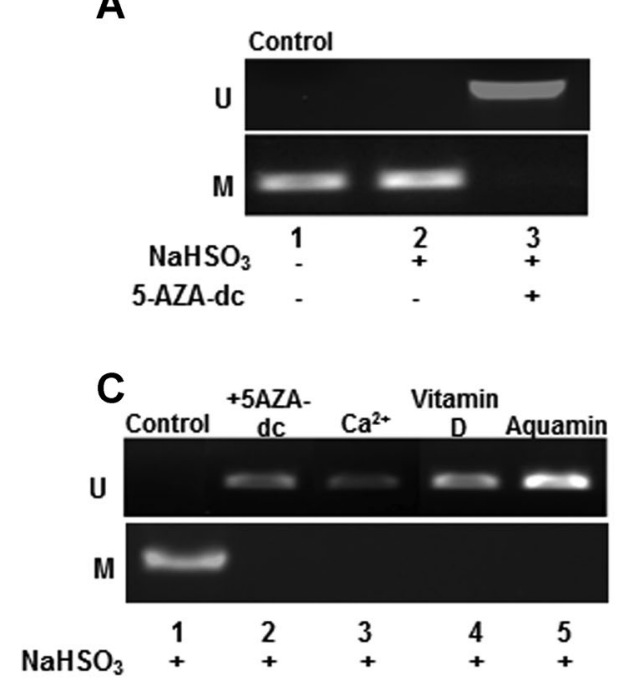

B

HCT116/CaSR null
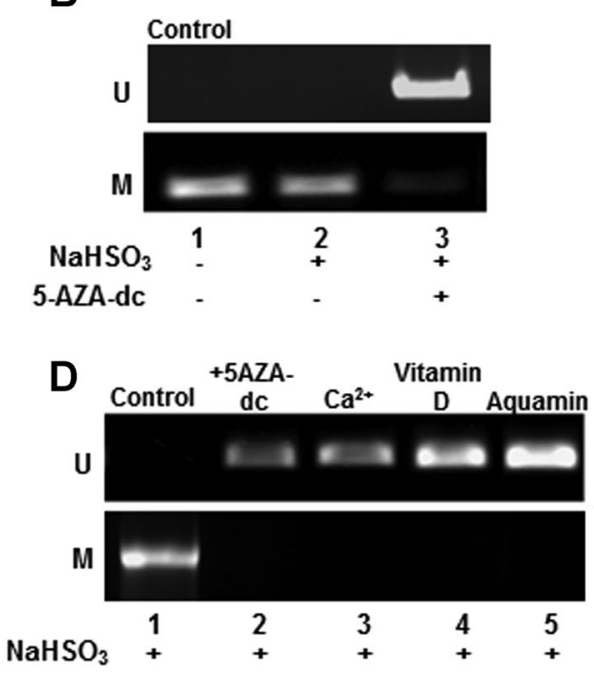

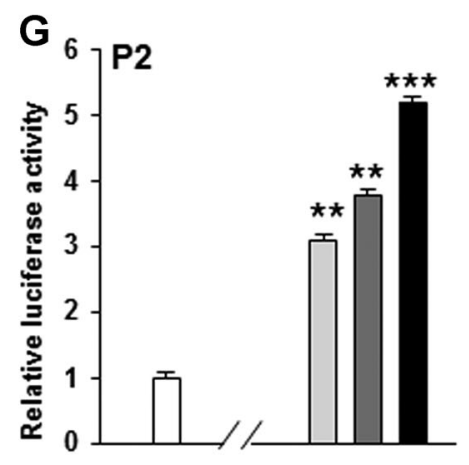

Figure 3. Demethylation of CaSR promoter and stimulation of CaSR promoter transcriptional reporter activities. Bisulfite and 5-aza-dc untreated or treated DNA was PCR-amplified using two different primers, one that amplifies unmethylated DNA $(U)$, and another amplifies methylated DNA (M). A and B, MSP analysis of CaSR promoter in null cells and demethylation of the promoter by 5-aza-dc. C and D, MSP analysis of CaSR promoter in null cells by treatment with 5 -aza-dc or treatment with $\mathrm{Ca}^{2+}(1.4 \mathrm{mM})$ or vitamin $\mathrm{D}(1 \mu \mathrm{M})$ or Aquamin $\left(\mathrm{Ca}^{2+} 1.4 \mathrm{mM} \mathrm{Ca}^{2+}\right)$.

markers in CaSR null cells [14] lend support to this hypothesis.

Previous studies have shown that $\mathrm{Ca}^{2+}$ or vitamin D can inhibit cell growth and induce CaSR expression in the parental CBS and HCT116 cells $[9,19]$. In the

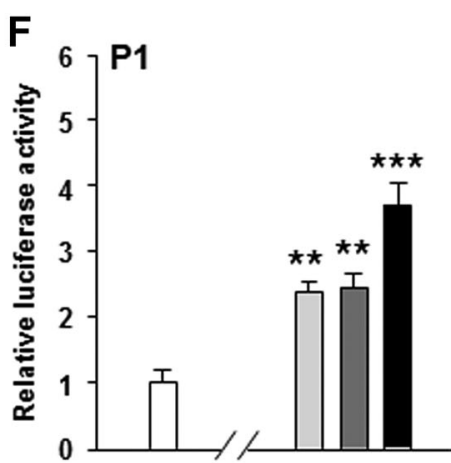

Control $\mathrm{Ca}^{2+}$

Vitamin D Aquamin

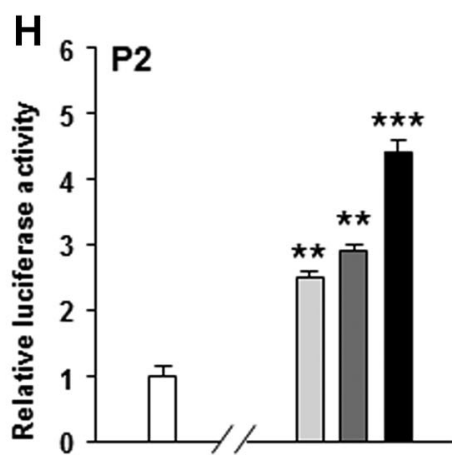

Cells were treated for $48 \mathrm{~h}$ prior to MSP analysis. $\mathrm{E}$ and $\mathrm{F}$, relative transcriptional activities of the P1 and $\mathrm{G}$ and $\mathrm{H}, \mathrm{P} 2 \mathrm{CaSR}$ promoter in the CaSR null cells treated with $\mathrm{Ca}^{2+}(1.4 \mathrm{mM})$ or vitamin $\mathrm{D}(1 \mu \mathrm{M})$ or Aquamin $\left(\mathrm{Ca}^{2+} 1.4 \mathrm{mM} \mathrm{Ca}^{2+}\right)$ for $48 \mathrm{~h}$. Triplicate determinations were performed in each experiments and the results shown represent the mean and standard error of three independent experiments. Asterisk (*) indicates the results are of statistical significance ${ }^{*} P<0.05$ significant ${ }^{* *} P<0.01$ very significant; ${ }^{* * *} P<0.001$ extremely significant.

present study, we first determined and compared the effectiveness of three CaSR agonists (i.e., $\mathrm{Ca}^{2+}$ alone, vitamin $\mathrm{D}$, and Aquamin) in growth inhibition and CaSR induction in the parental cells. We then extend the analysis to the isolated CaSR null cells cultured in 

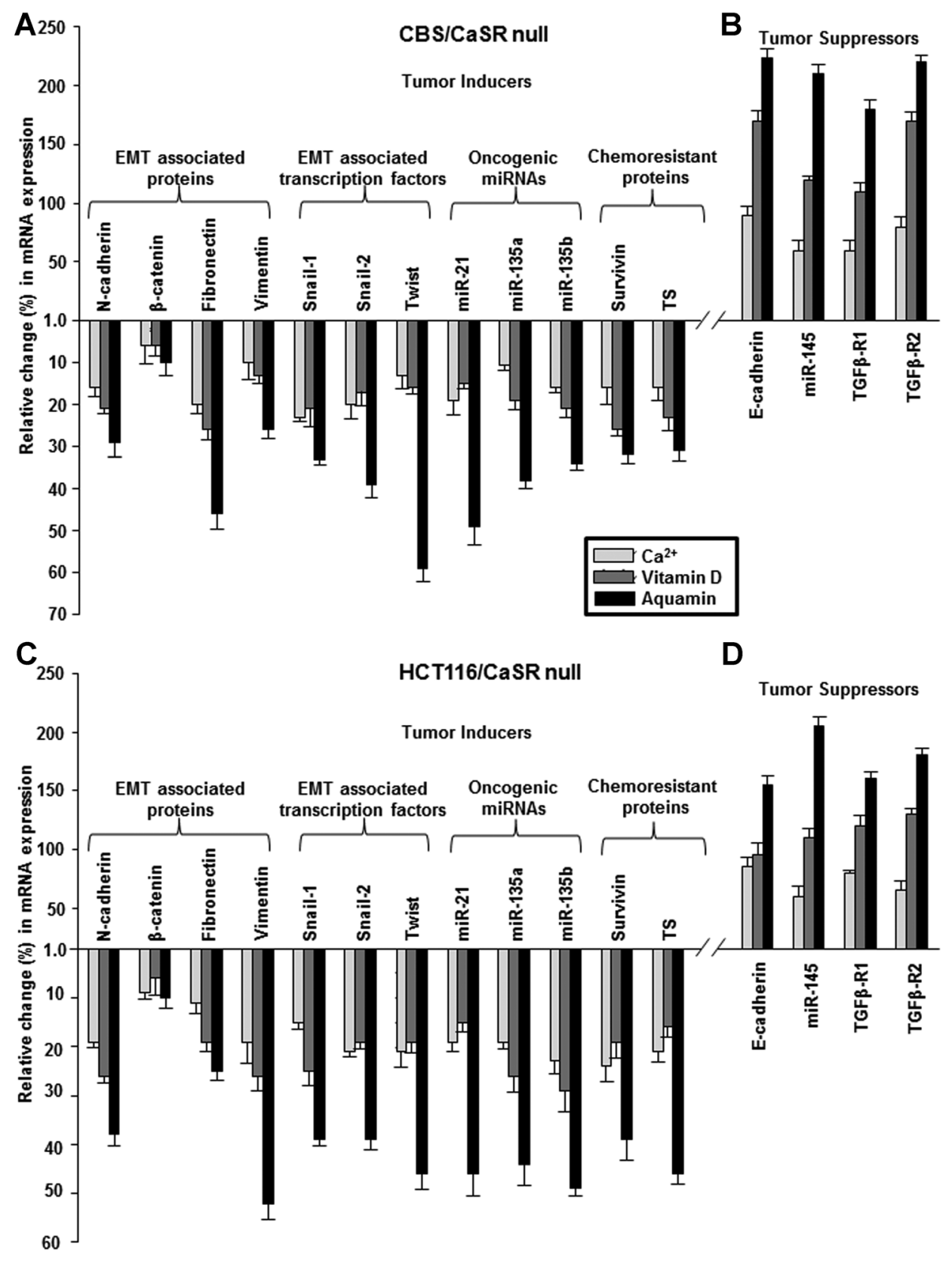

Figure 4. Real time RT-PCR analysis of the changes in the molecular profile of CaSR null cells upon CaSR induction. The gene expression profiles of treated CaSR null cells were compared to that of their corresponding control parental CBS and HCT116 cells. A and C, relative \% reduction in mRNA expression level encoding EMT associated molecules and transcription factors, oncogenic miRNA and chemoresistant proteins. $B$ and $D$, relative \% increase in mRNA expression encoding tumor suppressive mRNAs and miRNA. $\beta$-actin was used as loading controls for

hESC culture medium. With regard to the null cells, we also determined the effectiveness of the three agonists in altering the molecular phenotype of these cells. Overall, vitamin D was effective in inhibiting cell growth and inducing CaSR in both the parental and CaSR null cells, but required supra physiologic concentration $(1.0 \mu \mathrm{M})$ for activity. A physiologic concentration of $\mathrm{Ca}^{2+}(1.4 \mathrm{mM})$ provided either alone real time RT-PCR. Values were normalized and compared to that of untreated controls with a base line value of 1.0. Triplicate assays were performed in each experiment and the values shown represent the mean and standard error of three independent experiments. With the exception of the $\beta$-catenin expression profile in $A$ and the $\beta$-catenin expression profile in $C$ treated with vitamin $D$ the results obtained were of statistical significance (unpaired Student's $t$-test) with $P$ values ranging from 0.05 (significance) to 0.001 (extremely significant)

or as part of a multi-mineral-rich natural product was also effective in this regard. Compared to $\mathrm{Ca}^{2}$ alone, $\mathrm{Ca}^{2+}$ in conjunction with the other trace elements present in Aquamin had greater activity. Along with the induction of CaSR, Aquamin was also found to be more potent than $\mathrm{Ca}^{2+}$ or $1.0 \mu \mathrm{M}$ vitamin $\mathrm{D}$ in stimulating CaSR promoter reporter activities, demethylating the CaSR promoter and altering the 
molecular phenotype of the CaSR null cells maintained in hESC culture medium. Changes in the molecular phenotype include the down-regulated expression of EMT associated proteins and transcription factors and the up-regulated expression of the tumor suppressors E-cadherin, miR-145 and TGF $\beta$-R1 and TGF $\beta-R 2$. Interestingly, treatment of CaSR null cells with 5AZA-dc alone also results in the demethylation of CaSR promoter but without gene transcription. Thus, demethylation of these CpG islands alone is not sufficient to stimulate CaSR expression.

In the colonic crypts, how the expression of CaSR is regulated as the CaSR null crypt stem cells migrate and differentiate upwards in the direction of the lumen is unknown. The present studies, using isolated CaSR null cells, support our hypothesis that exposure to nutrients in the colonic fluids such as $\mathrm{Ca}^{2+}$, vitamin $\mathrm{D}$, and various other minerals could be the triggers. Presumably, the induction of CaSR would propel the crypt stem cells into the normal pathway of differentiation. In fact, in the colonic crypt, the fully differentiated cells at the apex of the crypt (where the $\mathrm{Ca}^{2+}$ concentration is highest) express the highest level of CaSR $[8,12]$. The expression of TGF $\beta$ in the colonic crypt has also been reported to be linked to differentiation - that is, there is a high level of TGF $\beta$ expression in the upper portion of a crypt by comparison to the lower portion of the crypt [29]. TGF $\beta$ is a potent growth inhibitor and differentiation promoter in colonic epithelial cells and mediates its action through TGF $\beta-R 1$ and TGF $\beta-R 2$ [30-32]. Interestingly, we recently found that in human colon carcinoma cells, responsiveness to TGF $\beta$ requires CaSR [25]. Thus, it is not surprising that TGF $\beta$ receptors were up-regulated along with the induction of CaSR.

The chemopreventive activity of $\mathrm{Ca}^{2+}$ in the colon is well established, based on both epidemiological and interventional studies [33-39]. While $\mathrm{Ca}^{2+}$ (alone or in conjunction with vitamin D) has acknowledged capacity to reduce polyp formation in the colon, its efficacy can be described as modest. It has been suggested that under conditions of optimal usage, a decrease in polyp formation of approximately $20 \%$ might be achieved [40]. Further, while $\mathrm{Ca}^{2+}$ supplements are generally considered safe, a meta-analysis of the $\mathrm{Ca}^{2+}$ supplementation literature came to the conclusion that long-term use of such supplements was associated with an increased risk of cardiovascular events [41]. In recent studies we demonstrated that Aquamin (i.e., the mineralized remains of the red marine algae, Lithothamnion sp.) reduced polyp formation in genetically normal mice on a high fat diet $[24,42]$. This natural product, which contains $\mathrm{Ca}^{2+}$ but also contains significant amounts of $\mathrm{Mg}^{2+}$ and detectable levels of 72 additional trace minerals, was more effective than $\mathrm{Ca}^{2+}$ alone at comparable $\mathrm{Ca}^{2+}$ levels [42]. In other studies, Aquamin was shown to be more effective than $\mathrm{Ca}^{2+}$ alone at suppressing proliferation and inducing differentiation in human colon cancer cells in vitro [43]. The present observation - that is, demonstrating increased effectiveness of Aquamin in up-regulating CaSR expression relative to $\mathrm{Ca}^{2+}$ alone - provides a plausible explanation for its enhanced efficacy. The molecular basis for the enhanced efficacy of Aquamin (relative to $\mathrm{Ca}^{2+}$ alone) is not fully understood. However, previous studies have demonstrated that several of the trace elements present in Aquamin are capable of binding to CaSR in place of $\mathrm{Ca}^{2+}$. Some of these, including members of the lanthanoid family of "rare earth" elements have a higher affinity for CaSR than $\mathrm{Ca}^{2+}$ itself $[44,45]$. Although the present studies demonstrate that Aquamin is more effective than $\mathrm{Ca}^{2+}$ alone or vitamin $\mathrm{D}$ at up-regulating CaSR expression (both in the parental lines and in the CaSR null cells), qualitatively, the three agonists are similar.

All three agonists demethylated the CaSR promoter, stimulated CaSR promoter reporter activities, and altered the molecular phenotype of the CaSR null cells maintained in hESC culture medium. Changes in the molecular phenotype included the down-regulated expression of several EMT-associated proteins and transcription factors and the up-regulated expression of the tumor suppressors including E-cadherin, miR145 and TGF $\beta-R 1$ and TGF $\beta-R 2$. Whether these agonists can induce similar molecular changes in CaSR null cancer cells or in the normal basal crypt stem cells in vivo, however, is unknown and will require further investigation. Thus, the data support the notion that modulating CaSR expression has "global" effects on growth and differentiation pathways in colonic epithelial cells. In colon carcinoma cells, the biologic action of vitamin D closely resembles that of CaSR $[9,46]$. The human CaSR gene has two promoters and each promoter has a transcriptional start site containing a vitamin D response elements $[28,47] . \mathrm{Ca}^{2+}$ or vitamin D can stimulate CaSR promoter activity and CaSR protein expression [9]. Much of the action of vitamin D in human colon carcinoma cells is dependent on CaSR expression and function because blocking the expression of CaSR by shRNA abrogates the biologic effects of vitamin D [19]. Thus, a strong molecular linkage exist between vitamin D and CaSR.

In summary, our data show that either $\mathrm{Ca}^{2+}$ or vitamin D could directly induce CaSR expression in colonic epithelial cells, leading to differentiation and growth reduction. However, Aquamin was more effective than either $\mathrm{Ca}^{2+}$ alone or vitamin $\mathrm{D}$ as a CaSR inducer. To the extent that these in vitro observations reflect responses occurring in the intact colon, these data help to understand how CaSR expression is regulated in the colon, and provide a rationale for the use of a multi-mineral approach in place of $\mathrm{Ca}^{2+}$ alone as a colon polyp/cancer chemopreventive. The efficacy of Aquamin needs to be confirmed in controlled clinical studies. 


\section{ACKNOWLEDGEMENT}

The support of Simmons Cancer Institute and grant 11-077 from the Association for International Cancer Research, St. Andrews, Scotland is gratefully acknowledged.

\section{REFERENCES}

1. Brown EM, Gamba G, Riccardi D, et al. Cloning and characterization of an extracellular $\mathrm{Ca}(2+)$-sensing receptor from bovine parathyroid. Nature 1993;366:575-580.

2. Brown EM, MacLeod RJ. Extracellular calcium sensing and extracellular calcium signaling. Physiol Rev 2001;81:239-297.

3. Hofer AM, Brown EM. Extracellular calcium sensing and signalling. Nat Rev Mol Cell Biol 2003;4:530-538

4. Gama L, Baxendale-Cox LM, Breitwieser GE. Ca ${ }^{2+}$-sensing receptors in intestinal epithelium. Am J Physiol 1997;273: C1168-C1175

5. Cheng I, Klingensmith ME, Chattopadhyay N, et al. Identification and localization of the extracellular calcium-sensing receptor in human breast. J Clin Endocrinol Metab 1998; 83:703-707.

6. McNeil L, Hobson S, Nipper V, Rodland KD. Functional calcium-sensing receptor expression in ovarian surface epithelial cells. Am J Obst Gynecol 1998;178:305-313.

7. Rutten MJ, Bacon KD, Marlink KL, et al. Identification of a functional $\mathrm{Ca}^{2+}$-sensing receptor in normal human gastric mucous epithelial cells. Am J Physiol 1999:277:G662-G670.

8. Chakrabarty S, Radjendirane V, Appelman H, Varani J. Extracellular calcium and calcium sensing receptor function in human colon carcinomas: Promotion of E-cadherin expression and suppression of beta-catenin/TCF activation. Cancer Res 2003;63:67-71.

9. Chakrabarty S, Wang $\mathrm{H}$, Canaff L, Hendy GN, Appelman $\mathrm{H}_{\text {, }}$ Varani J. Calcium sensing receptor in human colon carcinoma: Interaction with $\mathrm{Ca}(2+)$ and 1,25-dihydroxyvitamin $\mathrm{D}(3)$. Cancer Res 2005;65:493-498.

10. Bhagavathula N, Kelley EA, Reddy M, et al. Upregulation of calcium-sensing receptor and mitogen-activated protein kinase signalling in the regulation of growth and differentiation in colon carcinoma. Br J Cancer 2005;93:1364-1371.

11. Bhagavathula N, Hanosh AW, Nerusu KC, Appelman $H$ Chakrabarty S, Varani J. Regulation of E-cadherin and betacatenin by $\mathrm{Ca} 2+$ in colon carcinoma is dependent on calciumsensing receptor expression and function. Int J Cancer 2007:121:1455-1462.

12. Rogers AC, Hanly AM, Collins D, Baird AW, Winter DC. Review article: Loss of the calcium-sensing receptor in colonic epithelium is a key event in the pathogenesis of colon cancer. Clin Colorectal Cancer 2012;11:24-30.

13. Rey O, Chang W, Bikle D, Rozengurt N, Young SH, Rozengurt E. Negative cross-talk between calcium-sensing receptor and beta-catenin signaling systems in colonic epithelium. J Biol Chem 2012:287:1158-1167.

14. Singh N, Liu G, Chakrabarty S. Isolation and characterization of calcium sensing receptor null cells: A highly malignant and drug resistant phenotype of colon cancer. Int J Cancer 2013; 132:1996-2005.

15. Singh N, Promkan M, Liu G, Varani J, Chakrabarty S. Role of calcium sensing receptor (CaSR) in tumorigenesis. Best Pract Res Clin Endocrinol Metab 2013;27:455-463.

16. Hizaki $K$, Yamamoto $H$, Taniguchi $H$, et al. Epigenetic inactivation of calcium-sensing receptor in colorectal carcinogenesis. Mod Pathol 2011:24:876-884.

17. Liu G, Hu X, Varani J, Chakrabarty S. Calcium and calcium sensing receptor modulates the expression of thymidylate synthase, $\mathrm{NAD}(\mathrm{P}) \mathrm{H}$ :quinone oxidoreductase 1 and survivin in human colon carcinoma cells: Promotion of cytotoxic response to mitomycin C and fluorouracil. Mol Carcinog 2009;48: 202-211.
18. Laaksonen M, Karkkainen M, Outila T, Vanninen $T$, Ray $C$, Lamberg-Allardt C. Vitamin D receptor gene Bsml-polymorphism in Finnish premenopausal and postmenopausal women: Its association with bone mineral density, markers of bone turnover, and intestinal calcium absorption, with adjustment for lifestyle factors. J Bone Miner Metab 2002;20:383-390.

19. Liu G, Hu X, Chakrabarty S. Vitamin D mediates its action in human colon carcinoma cells in a calcium-sensing receptordependent manner: Downregulates malignant cell behavior and the expression of thymidylate synthase and survivin and promotes cellular sensitivity to 5-FU. Int J Cancer 2010; 126:631-639.

20. Chakrabarty S, Rajagopal S, Moskal TL. Protein kinase Calpha controls the adhesion but not the antiproliferative response of human colon carcinoma cells to transforming growth factor beta1: Identification of two distinct branches of post-protein kinase Calpha adhesion signal pathway. Lab Invest 1998; 78:413-421.

21. Singh N, Chakrabarty S. Induction of CaSR expression circumvents the molecular features of malignant CaSR null colon cancer cells. Int J Cancer 2013;133:2307-2314.

22. Liu G, Hu X, Premkumar L, Chakrabarty S. Nifedipine synergizes with calcium in activating the calcium sensing receptor, suppressing the expression of thymidylate synthase and survivin and promoting sensitivity to fluorouracil in human colon carcinoma cells. Mol Carcinog 2011;50:922-930.

23. Adey WH, Mckibbin DL. Studies on the maerl species Phymatolithon calcareum (Pallas) nov. comb. and Lithothamnium corallioides Crouan in the Ria de Vigo. Bot Mar 1970; 13:100-106.

24. Aslam MN, Paruchuri T, Bhagavathula N, Varani J. A mineralrich red algae extract inhibits polyp formation and inflammation in the gastrointestinal tract of mice on a high-fat diet Integr Cancer Ther 2010;9:93-99.

25. Singh N, Liu G, Chakrabarty S. Cellular responses to TGFbeta and TGFbeta receptor expression in human colonic epithelial cells require CaSR expression and function. Cell Calcium 2013;53:366-371

26. Brattain MG, Levine AE, Chakrabarty S, Yeoman LC, Willson JK, Long B. Heterogeneity of human colon carcinoma. Cancer Metastasis Rev 1984;3:177-191.

27. Taniguchi H, Yamamoto H, Akutsu N, et al. Transcriptional silencing of hedgehog-interacting protein by $\mathrm{CpG}$ hypermethylation and chromatic structure in human gastrointestinal cancer. J Pathol 2007;213:131-139

28. Chikatsu N, Fukumoto $S$, Takeuchi $Y$, et al. Cloning and characterization of two promoters for the human calciumsensing receptor (CASR) and changes of CaSR expression in parathyroid adenomas. J Biol Chem 2000;275:7553-7557.

29. Avery A, Paraskeva C, Hall P, Flanders KC, Sporn M, Moorghen M. TGF-beta expression in the human colon: Differential immunostaining along crypt epithelium. $\mathrm{Br} J$ Cancer 1993;68:137-139.

30. Chakrabarty S, Jan Y, Brattain MG, Tobon A, Varani J. Diverse cellular responses elicited from human colon carcinoma cells by transforming growth factor-beta. Cancer Res 1989;49:21122117.

31. Chakrabarty S, Fan D, Varani J. Modulation of differentiation and proliferation in human colon carcinoma cells by transforming growth factor beta 1 and beta 2. Int J Cancer 1990; 46:493-499.

32. Massague J. Receptors for the TGF-beta family. Cell 1992; 69:1067-1070.

33. McCullough ML, Robertson AS, Rodriguez C, et al. Calcium, vitamin D, dairy products, and risk of colorectal cancer in the Cancer Prevention Study II Nutrition Cohort (United States). Cancer Causes Control 2003;14:1-12.

34. Flood A, Peters U, Chatterjee N, Lacey JV, Jr., Schairer C, Schatzkin A. Calcium from diet and supplements is associated with reduced risk of colorectal cancer in a prospective cohort 


$$
\mathrm{Ca}^{2+}, \text { VITAMIN D AND AQUAMIN ACT THROUGH CaSR }
$$

of women. Cancer Epidemiol Biomar Prevent 2005;14:126132.

35. Wakai K, Hirose K, Matsuo K, et al. Dietary risk factors for colon and rectal cancers: A comparative case-control study. J Epidemiol 2006;16:125-135.

36. Bostick RM, Potter JD, Sellers TA, McKenzie DR, Kushi LH, Folsom AR. Relation of calcium, vitamin $D$, and dairy food intake to incidence of colon cancer among older women. The lowa Women's Health Study. Am J Epidemiol 1993;137:13021317.

37. Kampman E, Slattery ML, Caan B, Potter JD. Calcium, vitamin $D$, sunshine exposure, dairy products and colon cancer risk (United States). Cancer Causes Control 2000; 11:459-466.

38. Kampman E, Giovannucci $E$, van 't Veer $P$, et al. Calcium, vitamin $D$, dairy foods, and the occurrence of colorectal adenomas among men and women in two prospective studies. Am J Epidemiol 1994;139:16-29.

39. Baron JA, Beach M, Mandel JS, et al. Calcium supplements for the prevention of colorectal adenomas. Calcium Polyp Prevention Study Group. N Eng J Med 1999;340: 101-107.

40. Bostick RM, Goodman M, E. Sidelinkov E. Calcium and vitamin D. In: Potter JD, Lindor NM, editors. Genetics of colorectal cancer. New York, NY: Springer Science+Buisness Media, LLC; 2009. pp. 273-294.
41. Bolland MJ, Avenell A, Baron JA, et al. Effect of calcium supplements on risk of myocardial infarction and cardiovascular events: Meta-analysis. BMJ 2010;341:c3691.

42. Aslam MN, Bergin I, Naik M, et al. A multimineral natural product from red marine algae reduces colon polyp formation in C57BL/6 mice. Nutr Cancer 2012;64:1020-1028.

43. Aslam MN, Bhagavathula N, Paruchuri T, Hu X, Chakrabarty S, Varani J. Growth-inhibitory effects of a mineralized extract from the red marine algae, Lithothamnion calcareum, on $\mathrm{Ca}(2+)$-sensitive and $\mathrm{Ca}(2+)$-resistant human colon carcinoma cells. Cancer Lett 2009;283:186-192.

44. Pidcock E, Moore GR. Structural characteristics of protein binding sites for calcium and lanthanide ions. J Biol Inorg Chem 2001;6:479-489.

45. Huang Y, Zhou Y, Castiblanco A, Yang W, Brown EM, Yang JJ. Multiple $\mathrm{Ca}(2+)$-binding sites in the extracellular domain of the $\mathrm{Ca}(2+)$-sensing receptor corresponding to cooperative $\mathrm{Ca}(2+)$ response. Biochemistry 2009;48:388-398.

46. Palmer HG, Gonzalez-Sancho JM, Espada J, et al. Vitamin D(3) promotes the differentiation of colon carcinoma cells by the induction of E-cadherin and the inhibition of beta-catenin signaling. J Cell Biol 2001;154:369-387.

47. Canaff L, Hendy GN. Human calcium-sensing receptor gene. Vitamin D response elements in promoters P1 and P2 confer transcriptional responsiveness to 1,25-dihydroxyvitamin D. J Biol Chem 2002;277:30337-30350. 